\title{
Correction: Chantasart et al. "Structure Enhancement Relationship of Chemical Penetration Enhancers in Drug Transport across the Stratum Corneum" Pharmaceutics 2012, 4, 71-92
}

\author{
Doungdaw Chantasart ${ }^{1}$ and S. Kevin $\mathrm{Li}^{2, *(1)}$ \\ 1 Department of Pharmacy, Faculty of Pharmacy, Mahidol University, Bangkok 10400, Thailand; \\ doungdaw.cha@mahidol.ac.th \\ 2 Division of Pharmaceutical Sciences, College of Pharmacy, University of Cincinnati, Cincinnati, \\ $\mathrm{OH} 45267$, USA \\ * Correspondence: kevin.li@uc.edu; Tel.: +1-513-558-0977
}

Received: 12 November 2019; Accepted: 13 December 2019; Published: 18 December 2019

The authors wish to make the following corrections to their paper [1].

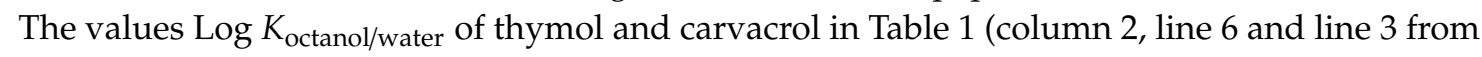
the bottom, respectively) are incorrect. With the correct values, the equation in Figure 4 (page 81) is also incorrect. The details of the corrections are described below.

1. Page 80: The correct values for the Log $K_{\text {octanol/water }}$ of thymol and carvacrol [2] in Table 1 are 3.30 and 3.49 , respectively.

2. Page 80: A new footnote (footnote $\mathrm{n}$ ) has been added in Table 1.

3. Page 81: The correct equation and $R^{2}$ in Figure 4 are $y=-0.982 x+0.371$ and $R^{2}=0.965$, respectively.

4. Page 92: A new reference (Reference 62) has been added [2].

These changes do not affect the conclusion of the paper. The authors would like to apologize for any inconvenience this might have caused.

\section{References}

1. Chantasart, D.; Li, S.K. Structure Enhancement Relationship of Chemical Penetration Enhancers in Drug Transport across the Stratum Corneum. Pharmaceutics 2012, 4, 71-92. [CrossRef] [PubMed]

2. Griffin, S.; Wyllie, S.G.; Markham, J. Determination of Octanol-Water Partition Coefficient for Terpenoids using Reversed-Phase High-Performance Liquid Chromatography. J. Chromatogr. A 1999, 864, 221-228. [CrossRef]

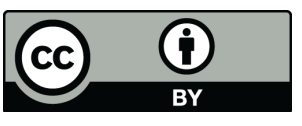

(C) 2019 by the authors. Licensee MDPI, Basel, Switzerland. This article is an open access article distributed under the terms and conditions of the Creative Commons Attribution (CC BY) license (http://creativecommons.org/licenses/by/4.0/). 